\title{
Vegetation structure and fire weather influence variation in burn severity and fuel consumption during peatland wildfires
}

\author{
G. M. Davies ${ }^{1,2}$, R. Domènech ${ }^{3,4}$, A. Gray ${ }^{5}$, and P. C. D. Johnson ${ }^{2}$ \\ ${ }^{1}$ School of Environment and Natural Resources, Kottman Hall, The Ohio State University, Columbus, Ohio, 43210, USA \\ ${ }^{2}$ Boyd Orr Centre for Population and Ecosystem Health, Institute for Biodiversity, Animal Health and Comparative Medicine, \\ University of Glasgow, Graham Kerr Building, Glasgow, G12 8QQ, UK \\ ${ }^{3}$ Solway Centre for Environment and Culture, University of Glasgow, Henry Duncan Building, Crichton University Campus, \\ Dumfries, DG1 4ZL, UK \\ ${ }^{4}$ Forest Sciences Centre of Catalonia (CTFC), Ctra. de Sant Llorenç de Morunys, Km 2, 25280 Solsona, Spain \\ ${ }^{5}$ Centre for Ecology and Hydrology, Bush Estate, Penicuik, Midlothian, EH26 0QB, UK
}

Correspondence to: G. M. Davies (davies.411@osu.edu)

Received: 28 July 2015 - Published in Biogeosciences Discuss.: 22 September 2015

Revised: 16 December 2015 - Accepted: 21 December 2015 - Published: 21 January 2016

\begin{abstract}
Temperate peatland wildfires are of significant environmental concern but information on their environmental effects is lacking. We assessed variation in burn severity and fuel consumption within and between wildfires that burnt British moorlands in 2011 and 2012. We adapted the composite burn index (pCBI) to provide semi-quantitative estimates of burn severity. Pre- and post-fire surface (shrubs and graminoids) and ground (litter, moss, duff) fuel loads associated with large wildfires were assessed using destructive sampling and analysed using a generalised linear mixed model (GLMM). Consumption during wildfires was compared with published estimates of consumption during prescribed burns. Burn severity and fuel consumption were related to fire weather, assessed using the Canadian Fire Weather Index System (FWI System), and pre-fire vegetation type. pCBI varied 1.6 fold between, and up to 1.7 fold within, wildfires. pCBI was higher where moisture codes of the FWI System indicated drier fuels. Spatial variation in pre- and post-fire fuel load accounted for a substantial proportion of the variance in fuel loads. Average surface fuel consumption was a linear function of pre-fire fuel load. Average ground fuel combustion completeness could be predicted by the Buildup Index. Carbon release ranged between 0.36 and $1.00 \mathrm{~kg} \mathrm{C} \mathrm{m}^{-2}$. The flammability of ground fuel layers may explain the higher $\mathrm{C}$ release-rates seen for wildfires in comparison to prescribed burns. Drier moorland community
\end{abstract}

types appear to be at greater risk of severe burns than blanketbog communities.

\section{Introduction}

Peatland wildfires pose a significant global challenge due to their potential for severe effects on ecosystem functioning and the detrimental role they may play in climate change. Peatlands account for approximately $2.5 \%$ of Earth's landcover (Kaat and Joosten, 2009) and contain more than $600 \mathrm{Gt}$ of stored carbon (Yu et al., 2010), equivalent to $25 \%$ of global soil organic carbon stocks (Mitra et al., 2005) and $75 \%$ of all atmospheric carbon (Kaat and Joosten, 2009). The degradation of this resource is a potential positive feedback to climate change and smouldering wildfires also have other significant environmental and human impacts such as respiratory problems associated with the inhalation of noxious smoke, the significant effort and costs involved in fire fighting, destruction of soil seedbanks, widespread plant mortality and post-fire erosion and water pollution problems (Watts and Kobziar, 2013). Increased fire risk and severity with climate change means wildfires pose a particularly significant threat to the ecological integrity and carbon stocks of peatlands (Turetsky et al., 2015).

The majority of research on the effects of peatland wildfires has come from tundra, boreal and tropical ecosystems 
(Turetsky et al., 2015). Temperate peatlands are also an important carbon store and habitat type but many have a long history of disturbance and management (e.g. Moore, 2002). British peatlands are acknowledged to be of significant national and international conservation importance though most have been subjected to a variety of land management practices, including burning and grazing, over at least the last two centuries (Bonn et al., 2009). Many peatlands have also been significantly impacted by drainage (Holden et al., 2004) and nutrient deposition from atmospheric pollution (Hogg et al., 1995). British peatland habitats contain fireprone vegetation including moorlands dominated by Calluna vulgaris L. Hull (hereafter Calluna) and a variety of mire and bog communities associated with Molinia caerulea (L.) Moench and Eriophorum spp. The majority of such habitats are underlain either by deep peat deposits or by shallower organic soils that nevertheless hold substantial amounts of carbon. Estimates suggest that around $88 \mathrm{tCha}^{-1}$ are stored in the soil and up to $2 \mathrm{tCha}^{-1}$ in the vegetation of dwarf shrub dominated moorlands in the UK (Ostle et al., 2009). The majority of the UK's $4.5 \mathrm{Tg}$ of soil carbon stocks are stored in peat deposits below heath, bog and moorland habitats (Bradley et al., 2005). Managed burning is an important control on the structure of these habitats with fires burnt regularly in both moorland and blanket bog habitats systems (Bonn et al., 2009). Recommended burn rotations are 1525 years for Calluna-dominated moorlands whilst longer rotations or no burning are recommended for wetter bog communities (Scottish Government, 2011). The role of fire in peatland ecology has become a highly controversial subject with substantial debate surrounding the effect of managed burning on ecosystem dynamics (e.g. Grant et al., 2012). The situation is not helped by a lack of data on how fire affects temperate peatland ecosystems such as those found in the UK. A number of studies have been completed but mostly for low-severity experimental prescribed burns (e.g. Davies et al., 2010) or for a few individual wildfire events (e.g. Davies et al., 2013; Maltby et al., 1990; Worrall et al., 2011). There is a consensus that wildfires pose a substantial and growing threat in the context of a changing climate (Bonn et al., 2009). In this context, data are urgently needed on both the scale of the wildfire problem and the effects of such burns.

In systems with peat or organic soils severe wildfires that ignite carbon-rich deposits can lead to substantial, instantaneous losses of carbon (Davies et al., 2013) and long-term changes to ecosystem function (Maltby et al., 1990). Whilst the severe effects of smouldering peat fires are obvious, such burns lie at one end of a spectrum of burn severity and not all fires on peatlands necessarily ignite peat or cause ecological damage. Indeed, carefully managed burning of peatlands can have a variety of ecosystem benefits (Davies et al., 2008a). Differences in burn severity can be caused by between and within site variation in fuel type and fuel structure as well as by differences in fire weather conditions (e.g. fuel moisture

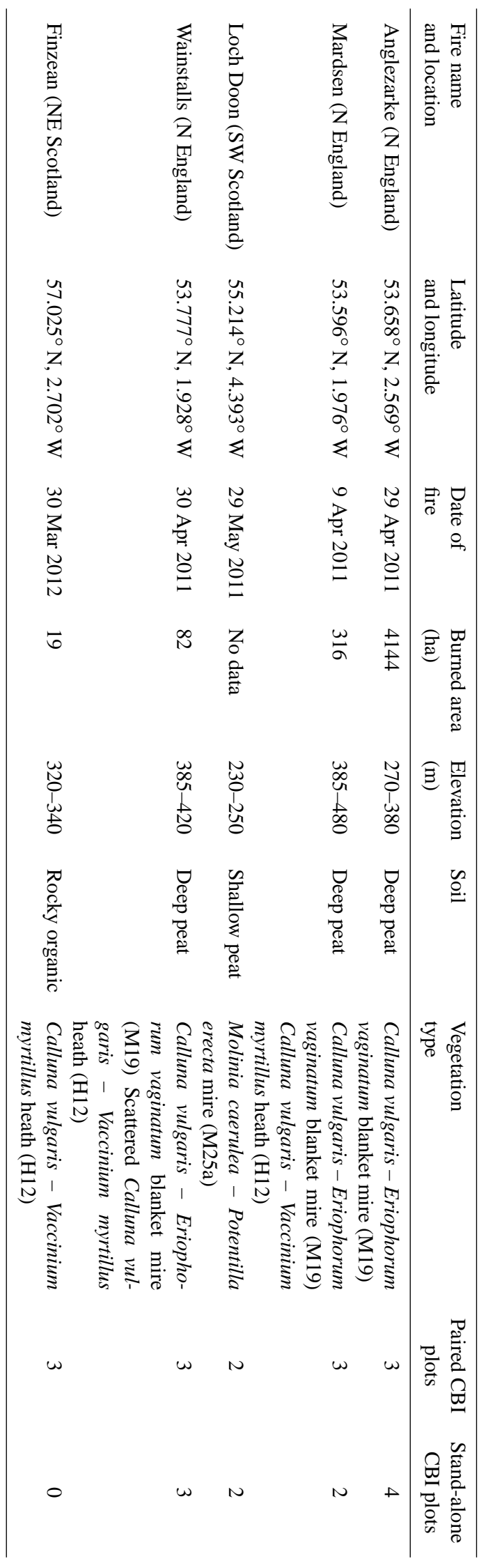


content, wind speed) across different burn days (Davies et al., 2010). In general this may mean that managed fires, typically burnt during low-severity conditions, have more limited effects than wildfires. Such patterns are not consistent as wildfires can occur in a wide variety of conditions and not all have particularly severe effects. Rather little effort has been made to try to capture or understand the effects of such variation but this is vital in order to monitor the amount of carbon released during wildfires and the extent of the environmental change they cause.

This research was initiated following severe wildfires during the springs of 2011 and 2012. We aimed to assess how burn severity varied within and between individual wildfires, and to define what the implications of such variation might be for carbon emissions due to wildfire and on-going development of fire danger rating systems such as the Met Office Fire Severity Index (MOFSI; Kitchen et al., 2006). MOFSI is based on the Canadian Fire Weather Index System (FWI System; Van Wagner, 1987) and has been implemented in Wales and England in order to provide a forecast of "exceptional" conditions when it becomes permissible to close open-access land under the Countryside and Rights of Way Act 2000. To date there have been limited efforts to examine the relationship between the FWI System and fire severity in the UK. There is some evidence its moisture codes relate fairly well to ground fuel (Legg et al., 2007) and peat (Krivtsov et al., 2008) moisture content, and that it can do a tolerable job of discriminating periods of increased wildfire risk (Legg et al., 2007). We aimed to investigate the relationship between fire severity and all the sub codes and indices of the FWI System but were particularly interested in its response to variation in the DMC (Duff Moisture Code), the DC (Drought Code) and the BUI (Build-up Index). The DMC and DC are designed to relate, respectively, to the moisture content of duff (partly decomposed litter) and compacted deeper organic layers. Such fuel layers bear some resemblance to the moss and/or litter layers and peat deposits found in British peatland ecosystems. The BUI integrates DMC and DC to provide an overall indication of fuel availability. Our specific objectives were to develop a simple methodology to assess variation in burn severity post hoc; assess the extent to which burn severity and fuel consumption vary within and between wildfires; and to investigate links between burning conditions (fuel type and fire weather) and variation in burn severity and fuel consumption.

\section{Material and methods}

\subsection{Study sites}

Monitoring was completed on five different wildfires (Table 1) that burnt British peatlands during the springs of 2011 and 2012. Sites were selected from information on fires provided by land-managers, public and private land-owners, government agencies and Fire and Rescue Services. We selected five sites that represented fires displaying moderate to high burn severity and the north-south and west-east range of bioclimatic conditions of the British uplands.

Pre-fire biotic and abiotic conditions varied both within and between our study sites (Table 1). Most locations in England were broadly classified as mires on deep peat with vegetation dominated by Calluna and Eriophorum vaginatum L. along with species such as Vaccinium myrtillus L., Deschampsia flexuousa (L.) Trin. and Trichophorum caespitosum (L.) Hartm. Vegetation was underlain by mats of pleurocarpous mosses. A number of plot locations were recorded at noticeably wetter locations. Here Calluna was less dominant, Eriophorum spp. and T. caespitosum occasionally very abundant and ground layer vegetation included patches of Sphagnum. Sites in Scotland represented opposite ends of the spectrum of peatland habitat types found in Britain. Finzean was comparatively drier, had shallow, stony organic soils and vegetation dominated by a mixture of Calluna and Pteridium aquilinum (L.) Kuhn. The site at Loch Doon was a bog with true peat soils and vegetation dominated by Molinia caerulea (L.) Moench, Myrica gale L. and Sphagnum spp.

\subsection{Field data collection}

Burn severity and fuel consumption sampling was performed approximately 6 months after the fires occurred. Previous researchers have collected such data as much as a year after fire (e.g. de Groot et al., 2009). Wildfires are sporadic, unpredictable events meaning sites had not been surveyed prior to the burns. Similar to other studies (e.g. Kasischke and Johnstone, 2005; Hollis et al., 2007; de Groot et al 2009), we used paired plots with burnt and/or unburnt subplots located across the fire perimeter (see Supplement Fig. S1). Two or three paired plots were located within each fire and chosen to represent the range of burn severities visible during a detailed site reconnaissance with local stakeholders. Many peatlands in the British uplands have a patchwork of fuel structures produced by managed burning. We were therefore careful to ensure that subplots were established where, following observation of stem basal diameters and stem density and discussion with local land-managers, we were confident that pre-fire fuel conditions across the fire-line were similar. Plots were also only established in regions of the fireline known to have been actively extinguished. In order to capture additional information about variation in burn severity we established a number of unpaired plots within the interior of each fire (Table 1). Unburnt areas were not available for comparison with these plots and they were only used to explore variation in burn severity.

\subsection{Fire weather}

Variation in burning conditions between the fires was described using the FWI System (Van Wagner, 1987). The FWI 
System requires daily data on wind speed, temperature and humidity at 12 noon as well as $24 \mathrm{~h}$ accumulated rainfall. These were extracted from the British Atmospheric Data Centre database for the nearest weather station to each of the wildfires (mean distance $=15 \mathrm{~km}, \max =31 \mathrm{~km}$ ). Rainfall data were available from rain gauges closer to the fire site than the nearest full weather station and we used these to estimate precipitation (mean distance $=5 \mathrm{~km}, \max =10 \mathrm{~km}$ ). Available data on $24 \mathrm{~h}$ accumulated rainfall was 09:00-09:00 rather than noon to noon though the difference is unlikely to be of importance. FWI System values were calculated using the package "fume" (Santander Meteorology Group, 2012) in R 3.1.2 (R Development Core Team, 2014). Some of the moisture codes and indices of the FWI System have long lag times ( 52 days for the Drought Code) so values were calculated with a 90-day lead-in.

\subsection{Assessing burn severity}

To assess burn severity we adapted the Composite Burn Index (Key and Benson, 2006) which was developed in the USA to allow semi-quantitative assessment of burn severity and ground-truthing of remotely sensed data (e.g. Miller and Thode, 2007). The CBI uses a scoring system to visually estimate a fire's impact on components of each of five fuel strata. For instance, assessment of "substrates" considers consumption of downed fuels of a variety of size classes (litter up to heavy fuels $>8$ inches diameter), consumption of duff layers and changes to the cover and colour of soil and rock. Similarly to Schepers et al. (2014), we adapted the CBI to account for the unique vertical structure and fuelbeds of treeless peatland habitats and, specifically, to include the impact of fire on peat-building Sphagnum species. We recorded severity in circular plots $20 \mathrm{~m}$ in diameter (Supplement Fig. S1) according to two strata - substrates (soil, litter and mosses) and the field layer (dwarf shrubs and graminoids; see Supplement Table S1). All variables were rated on a scale of 1-3 with individual ratings averaged within strata and then summed across the strata. Any variable that was not relevant, or which could not be recorded, for a particular plot was disregarded. A full protocol and data collection sheet for using the peatland CBI methodology (pCBI) are provided in the Supplement.

\subsection{Estimating fuel consumption}

We assessed fuel consumption in two pCBI burnt-unburnt paired plots for each fire. Within both the burnt and unburnt subplots we randomly located two fuel quadrats $\left(0.25 \mathrm{~m}^{2}\right)$ and five gas-flux chambers $\left(0.12 \mathrm{~m}^{2}\right)$. All biomass above the top of the peat was harvested in each quadrat/chamber. A total of 14 biomass estimates were thus available for each plot - seven from burnt and seven from unburnt subplots. Harvested vegetation was separated into the following categories: dwarf shrubs, graminoids, ferns (P. aquilinum), pleurocarpous mosses and plant litter, Sphagnum spp., tussock bases of M. caerulea and/or Eriophorum spp. and woody stems buried in the moss and litter. During analysis, the first three categories were grouped into a surface fuel category whilst the mosses, litter, tussock bases and buried stems were classified as ground fuels. Material was dried for $48 \mathrm{~h}$ at $80^{\circ} \mathrm{C}$.

Fuel consumption in our wildfires was compared with values reported by Legg et al. (2007) for 26 experimental prescribed burns in Calluna-dominated moorland fuel types. Legg et al. (2007) used a non-destructive method, based on visual obstruction of a measuring stick (Davies et al., 2008b), to estimate pre-fire surface and ground fuel loads. Post-fire surface fuel loads were estimated via destructive harvesting. We estimated ground fuel consumption in these fires by using the reported mean change in moss/litter layer depth following burning and in the equation in Davies et al. (2008b) which relates moss/litter layer depth $D_{\mathrm{m}}, \mathrm{cm}$ ) to ground fuel biomass $\left(B_{\mathrm{g}}, \mathrm{g} \mathrm{m}^{-2}\right.$; Eq. 1$)$.

$B_{\mathrm{g}}=407+171 \times D_{\mathrm{m}}$

\subsection{Data analysis}

We analysed burn severity data at the plot-level, in essence treating each plot as a separate observation of fire effects and burn severity. We believe that this is valid because substantial variations in vegetation type and fuel structure across the fire ground and changes in fire weather during the course of the burn day mean fire behaviour can be considered independent at each plot. This approach is frequently used in wildland fire research as obtaining numerous observations of individual fires is often impossible (e.g. Fernandes et al., 2000; de Groot et al., 2009). The relationship between pCBI and FWI system codes was analysed graphically and using correlation analysis (Pearson product-moment correlation in the "cor.test" function in R 3.1.2; R Core Team, 2014).

We used a generalised linear mixed model (GLMM) with a normal error distribution to investigate spatial variation in estimated fuel consumption. The aim of our analysis was to partition variance in our data to understand how fuel consumption varies at multiple scales (i.e. between fires, plots within fires and within plots) and how this contributes to uncertainty in estimates of fuel consumption. We were not interested in testing the hypothesis that there is a difference in biomass between burnt and unburnt plots as this is not particularly enlightening. The GLMM was run with plot and fire site defined as random effects whilst status (burnt/unburnt) and sample type (chamber/quadrat) were defined as fixed effects. Including plot as a random effect accounts for the paired burnt-unburnt subplots design of our experiment. We selected the best fitting model by comparing a full model and a minimal model. The minimal model contained all sources of variation intrinsic to the design: the main effects of status and sample type, and random intercepts at the plot and fire levels. The full model additionally allowed the effect of status to vary between sample types (fitted as an interaction 
between status and sample type), and between plots and fires (fitted as random slopes at the plot and fire levels). Analysis started with the full model and simplification proceeded by null hypothesis testing, dropping non-significant effects. Random effects were tested first, using parametric bootstrapping with 10000 replicates (Faraway, 2005), dropping effects where $P>0.1$. Fixed effects were then tested using likelihood ratio tests, dropping effects where $P>0.05$. We justify using a less stringent significance level for random effects on the basis that power for testing random effects is generally low with few random effect levels, and incorrectly dropping a random effect due to a false negative test result can result in over-precise (anti-conservative) fixed effect estimates (Schielzeth and Forstmeier, 2009). We used parametric bootstrapping with 10000 replicates to estimate confidence intervals around mean plot-level consumption. This process was used to fit separate models for both ground and surface fuel consumption. Fuel consumption was square-root transformed to improve the fit of the residuals to a normal distribution. Log transformation was also considered but provided a poorer fit (see Fig. S2 for dot plots showing the raw data distributions, Supplement). There is debate in ecology about the usefulness of $P$ values (Ellison et al., 2014) and we do not report them. Rather we report the explanatory power of the final selected models and the variance explained by different levels of our experimental design. Thus, for the final, reduced models we used the procedures described by Nakagawa and Schielzeth (2013) and Johnson (2014) to calculate marginal and conditional $R^{2}$ values. These describe the explanatory power of the fixed effects and the whole model (fixed + random effects) respectively. As an initial step in this analysis we were also able to partition the variance in our data into that related to the fixed effects and the random effects of plot and fire. We assumed that residual variance was the result of within subplot variation in load between samples.

We examined controls on mean fuel consumption by combining the estimates of fuel consumption during wildfires produced by the GLMM analysis with information available from the prescribed fires reported by Legg et al. (2007). This allowed us to examine how mean ground and surface fuel consumption varies over a wider range of fire weather conditions. We used the "lm" function in $\mathrm{R}$ to model changes in the consumption and combustion completeness of surface and ground fuels as a function of pre-fire fuel load and fire weather.

\section{Results}

\subsection{Variation in burn severity}

There was substantial variation in burn severity both within and between individual fires (Fig. 1). On average, mean pCBI varied 1.6 fold between wildfires but up to 1.7 fold within

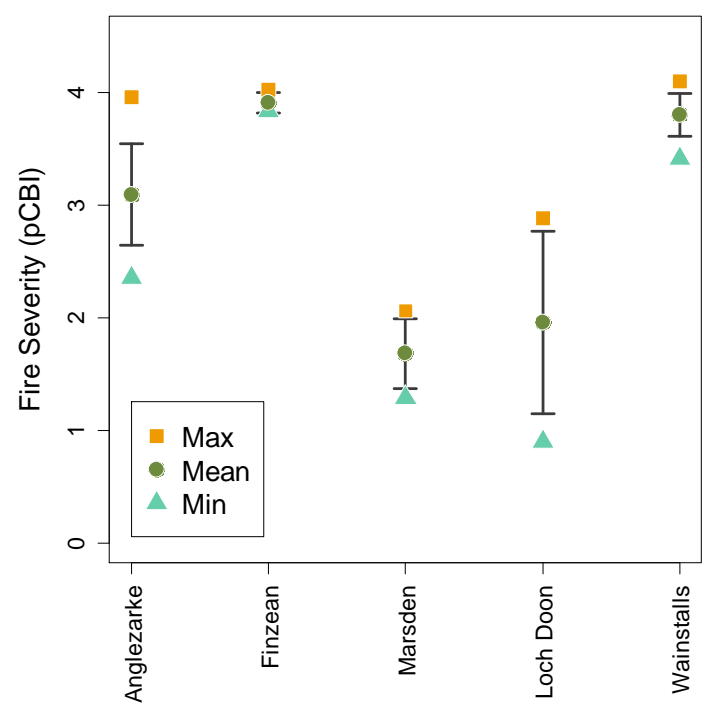

Figure 1. Variation in burn severity (peatland Composite Burn Index; pCBI) within and between five UK wildfires and across all 25 paired and unpaired pCBI plots. Error bars are $95 \%$ confidence intervals for the mean.

fires. Variability in burn severity was particularly substantial in the Anglezarke and Loch Doon wildfires. Examining the relationship between plot vegetation community, fire weather conditions and pCBI suggested potential interactions between these variables (Fig. 2). In general, pCBI appeared to increase with higher DMC $\left(r=0.80, P=6.4 \times 10^{-4}\right)$ and DC $\left(r=0.68, P=7.9 \times 10^{-3}\right)$ values. Plots in drier Calluna-dominated communities (National Vegetation Community H12) appeared to burn at high severities at lower DMC and DC values than wetter bog and mire communities (NVC M19, M20, M25a). However, fire sites with more varied vegetation community structure did not necessarily show the greatest amount of variation in fire severity.

\subsection{Variation in fuel consumption}

Both surface and ground fuel consumption were best represented by a model which included the fixed effects of plot status (burnt/unburnt), sample type (quadrat/chamber), random intercepts for individual fires and plots within fires, and random slopes for the effect of status within individual plots (Table 2). Plot status had considerably greater explanatory power for surface fuel loads compared to ground fuel loads where random factors attributable to variation in load between fires, plots and samples explained a greater proportion of the variance. There was considerable variation in fuel consumption both within and between different wildfires (Fig. 3), indeed variability within some fires was greater than that seen, on average, between fires.

For surface fuels there was a positive linear relationship between pre-fire fuel load and mean fuel consumption irrespective of fire type (Fig. 4). Surface fuel consumption $\left(C_{\mathrm{S}}\right)$ 
Table 2. Summary of the linear mixed model analyses on surface and ground fuel consumption showing. Top: the proportion of variance explained by each component of the models (the marginal and conditional $R^{2}$, respectively, show the explanatory power of the fixed effects and the whole model); and bottom: the magnitude of the fixed-effects' terms in the model where "Estimate" is the increase in the square-root of fuel load in comparison to the reference level (burnt or gas flux chamber for status and sample type respectively). SE $=$ standard error.

\begin{tabular}{lccccc}
\hline Model & $\begin{array}{c}\text { Fixed effects } \\
\left(\text { marginal } R^{2}\right)\end{array}$ & $\begin{array}{c}\text { Random effects } \\
\text { Fire }\end{array}$ & $\begin{array}{c}\text { Fixed + random effects } \\
\text { Plot }\end{array}$ & $\begin{array}{c}\text { Residual } \\
\left(\text { conditional } R^{2}\right)\end{array}$ \\
\hline Surface fuels & 48 & 5 & 24 & 77 & 23 \\
Ground fuels & 30 & 12 & 29 & 71 & 29 \\
\hline \multirow{2}{*}{ Model } & Fixed effect & Estimate & SE & 9.11 \\
\hline \multirow{2}{*}{ Surface fuels } & Status - Unburnt & 0.51 & 0.056 & 3.27 \\
& Sample - Quadrat & 0.11 & 0.034 & 6.62 \\
\multirow{2}{*}{ Ground fuels } & Status - Unburnt & 0.49 & 0.074 & 2.23 \\
& Sample - Quadrat & 0.10 & 0.046 & \\
\hline
\end{tabular}
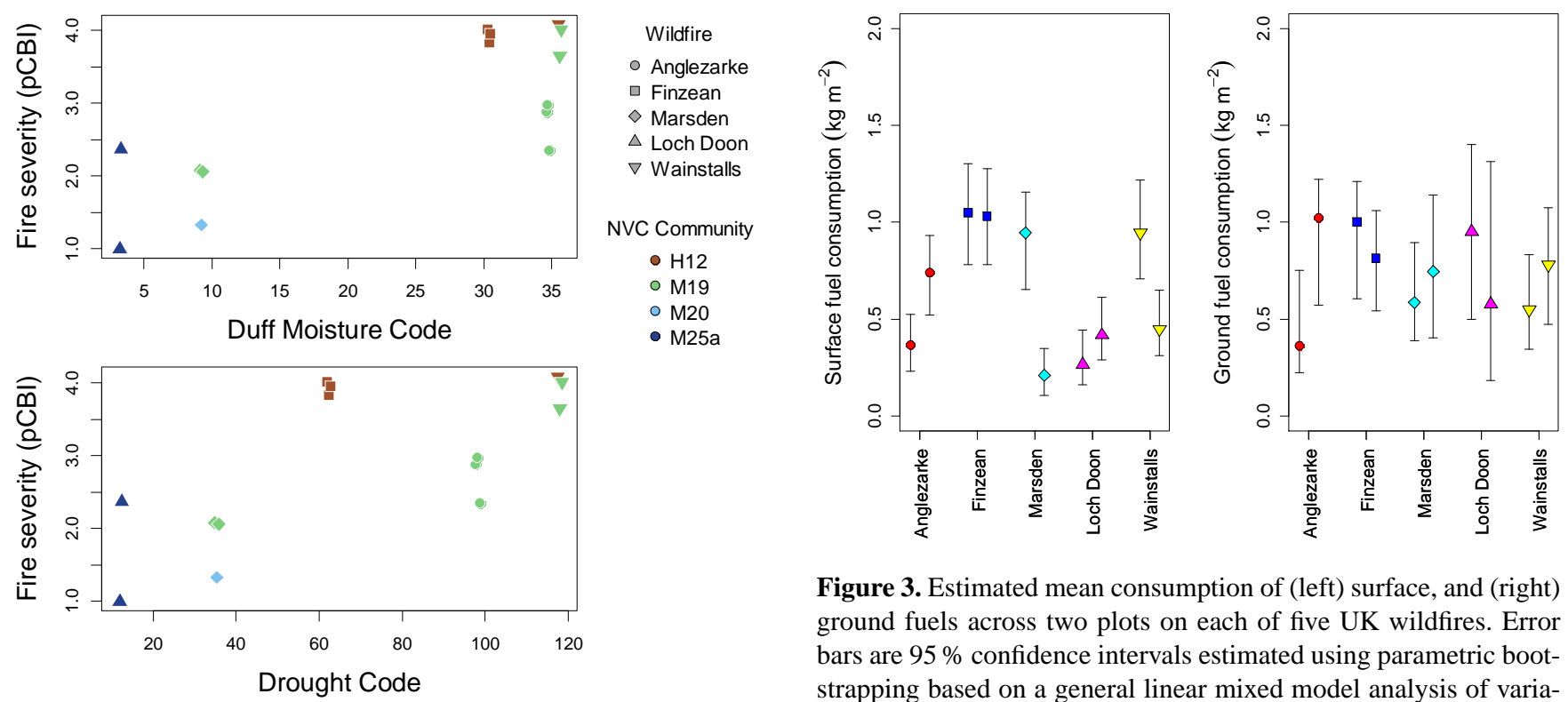

Figure 3. Estimated mean consumption of (left) surface, and (right) ground fuels across two plots on each of five UK wildfires. Error bars are $95 \%$ confidence intervals estimated using parametric bootstrapping based on a general linear mixed model analysis of variation in consumption (Table 3).

Figure 2. The relationship between burn severity as estimated by the peatland composite burn index, ecosystem type (National Vegetation Classification community; Rodwell, 1991) and moisture codes of the Canadian Fire Weather Index system. Only data for the 14 paired burnt-unburnt pCBI plots were available. Codes shown are the Duff Moisture Code (DMC; relating to loosely compacted organic layers of moderate depth) and the Drought Code (DC; relating to the moisture content of peat and layers of organic soil). Individual wildfires are shown as different symbol shapes, colours relate to NVC vegetation community (see Table 1 for NVC community descriptions).

was best predicted by pre-fire fuel load $\left(L_{\mathrm{s}} ; R_{\text {adj }}^{2}=0.73\right.$, $P=1.79 \times 10^{-11} ;$ Eq. 2). None of the FWI System values were significant or substantially improved the model fit. For ground fuels, the relationship between pre-fire fuel load and mean fuel consumption was noticeably different with a positive, linear relationship for wildfires but little change in con-

sumption with load for prescribed fires (Fig. 4). Ground fuel consumption and ground fuel combustion completeness appeared to decline with ground fuel load (Fig. 4). It proved difficult to develop a satisfactory model of ground fuel consumption, but ground fuel combustion completeness $\left(P_{\mathrm{g}}\right)$ could be predicted tolerably well as an asymptotic function of BUI (B; $R_{\text {adj }}^{2}=0.77, P=1.77 \times 10^{-12} ;$ Eq. 3$)$.

$C_{\mathrm{s}}=0.173+0.624 \times L_{\mathrm{s}}$

$P_{\mathrm{g}}=\sqrt{-0.034+0.020 \times B}$. 

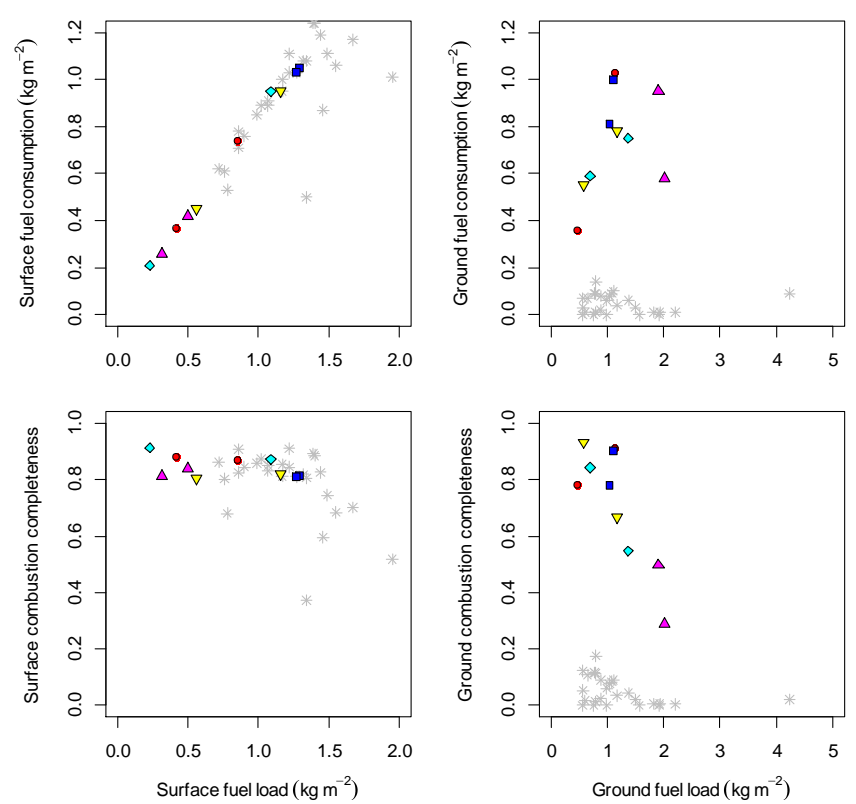

Figure 4. The relationships between mean pre-fire fuel load and mean fuel consumption for surface and ground fuels (top left and right respectively); and mean pre-fire fuel load and mean combustion completeness of surface and ground fuels (bottom left and right). Stars are experimental prescribed burns (see Legg et al., 2007), all other symbols are wildfires. The colours and shapes of the points for wildfires follows Fig. 3.

\section{Discussion}

Wildfires are variable in every aspect and the fires we were able to assess do not capture the full range of possible conditions. Notably, none of our fires displayed peat smouldering outside of isolated "hotspots". Nevertheless, this work represents the first multi-site attempt to investigate the relationship between burning conditions and wildfires' ecosystem effects on moorlands. Wildfires on peatlands are recognised as a growing global challenge with the potential to develop into a significant positive feedback to climate change (Kettridge et al., 2015). Scientists and land-managers currently have a limited understanding of the extent and causes of variation in the severity and ecological effects of temperate peatland fires. Temperate peatlands, such as those found in the $\mathrm{UK}$, are likely to be at the forefront of the effects of climate change with some studies suggesting considerable declines in their bioclimatic space (Gallego-Sala and Prentice, 2013) and fundamental changes in state associated with even moderate reductions in water tables (Kettridge et al., 2015). UK peatlands are of particular management concern due to the substantial area that has already been lost or degraded by changing land-management, and debates over the effects of traditional managed burning on the ecosystem services they provide (Bonn et al., 2009).
The growing peatland wildfire problem demands evidence to inform management and solve on-going conflict about the impacts of burning. Our adapted version of the CBI provides a method for rapid cataloguing of post-fire effects and burn severity in UK peatland ecosystems. The pCBI method appeared to function well and detected substantial differences in burn severity between and within individual fires. Importantly, there was evidence that increased pCBI can be attributed to reduced ground fuel layer moisture content as higher burn severity in British peatland ecosystems was recorded at higher values of DMC and DC (Fig. 2). Our results, and existing evidence that the DC may relate to the potential for smouldering peat fires (Davies et al., 2013), raise the prospect that it will be possible to forecast the potential for damaging wildfires. There was also a suggestion that burn severity is a function of ecosystem type, and associated site hydrology, as we recorded higher severity burns in dry moorland sites than would be expected given the intermediate DMC/DC values at which they occurred (Fig. 2). Sites with thin organic soils may thus be at greater risk of severe and smouldering wildfires than those with deeper peat and forecasts for such systems should be developed separately.

\subsection{Variation in fuel consumption}

In general, the random factors in our GLMM that account for variation in loads within plots and within and between fires, explained for as much, if not more, of the variation in fuel loads across our survey than differences between burnt/unburnt subplots. This was particularly true for ground fuels where $70 \%$ of the variance was attributable to spatial variation rather than the effects of fire or sample type. For ground fuels, the higher variance explained by random factors is possibly a function of the substantial differences in their composition between sites and, at some locations, between plots. Our sites included both bog communities with substantial cover of Sphagnum spp. and drier sites with thin organic soils where bryophyte communities were poorly-developed and ground fuels were dominated by litter. When considering the wildfires alone, ground fuel consumption showed a linear relationship with pre-fire fuel load though there was some evidence of a possible interaction with ecosystem type. Shetler et al. (2008) demonstrated that the presence of Sphagnum had a limiting effect on total carbon release during fires in black spruce forest peatlands and combustion completeness was lowest at Loch Doon, the wettest of our sites, where Sphagnum spp. and Molinia tussocks comprised a substantial proportion of the ground fuel load Fig. 4. However, this fire also occurred under the least severe fire weather conditions (Fig. 2).

When we analysed ground fuel consumption for the wild and prescribed fires together we were unable to develop a tolerably robust model. We hypothesise that this was due to differences in combustion rates between ecosystem types. Given that all our prescribed fires were in drier Calluna- 
dominated heathlands, our current data set was not sufficient to model ecosystem-specific rates. de Groot et al. (2009) examined variation in ground fuel consumption, albeit in nonpeatland systems, and also found differences in the controlling relationships for different fuel types. We were, however, able to predict combustion completeness based on BUI. These results are significant because (i) it provides further evidence that the moisture status of ground fuel layers is a critical control on burn severity in peatlands; (ii) it further demonstrates that certain components of the FWI System (DMC, DC and BUI) may be useful in forecasting potential burn severity.

Surface fuel consumption also showed significant spatial variation, though variability between plots explained a greater proportion of the variance than that between fires (Table 2). Surface fuel consumption of shrubs and graminoids was strongly related to pre-fire fuel load (Fig. 4, Eq. 2) and there was no significant effect of fire weather conditions. This matches some of our existing understanding of fire behaviour in moorland fuel types (Legg et al., 2007). In the vast majority of cases a relatively constant proportion of fuel is consumed as the fire spreads through the Calluna canopy consuming fine fuel particles but leaving larger live basal stems unburnt. Coarse woody, live fuels form a larger proportion of the fuel in older stands (Davies et al., 2008b) but rarely burn except under exceptionally severe conditions. This accounts for the decline in combustion completeness with increasing fuel load (Fig. 4). The variability we recorded in fuel consumption within and between our fires is likely to be attributable to (i) differences in fuel load between ecosystems; and (ii) the highly-managed nature of many UK peatlands where rotational patch burning produces a mosaic of fuel/habitat loads across the landscape.

Assuming that the approximate carbon content of our fuels was $49 \%$ (Worrall et al., 2013), our data suggest that average carbon release from the combustion of aboveground biomass by wildfires can range between 0.36 and $1.00 \mathrm{~kg} \mathrm{C} \mathrm{m}^{-2}$. This is somewhat greater than was seen for the prescribed fires which saw $\mathrm{C}$ release rates of between 0.26 and $0.66 \mathrm{~kg} \mathrm{C} \mathrm{m}^{-2}$. Our wildfire $\mathrm{C}$ release rates are considerably higher than the mean release of $0.15 \mathrm{~kg} \mathrm{C} \mathrm{m}^{-2}$ reported by Clay and Worral (2011) for the single moorland wildfire they studied, but both their result and ours falls within the range reported by Poulter et al. (2006) for a temperate peatland wildfire in North Carolina, USA. Whether or not leaving a peatland unburnt would increase the amount of carbon stored in the landscape is difficult to judge from our data alone. Whilst unmanaged peatlands may store greater amounts of $\mathrm{C}$ in surface and ground fuel layers than those that are subject to regular managed burning, they may also be more susceptible to large-scale wildfires because of their unmanaged fuel loads (Allen et al., 2013). Our results show rates of fuel consumption during such wildfire events will also be higher.

\section{Conclusions}

Burn severity varies considerably in relation to fuel structure and fire weather. To date much of the research on the effects of fire on moorlands has drawn an artificial distinction between the effects of prescribed burning and wildfires, though the latter do seem to be associated with increased severity. Our results suggest that critical differences in burn severity and fuel consumption can be linked to the flammability of ground fuel layers. Our data add to the information available to researchers modelling the effects of landmanagement and fire regimes on ecosystem carbon dynamics but we urge caution in their use and suggest that further work to determine linkages between burning conditions and both short- and long-term fire effects is urgently needed in temperate peatland ecosystems.

\section{The Supplement related to this article is available online at doi:10.5194/bg-13-389-2016-supplement.}

Author contributions. G. M. Davies designed the study, assisted with fieldwork, analysed the data and wrote the manuscript; R. Domènec completed the fieldwork and assisted in analysing the data and writing the manuscript; P. C. D. Johnson designed the mixed effects modelling element of the analysis and wrote the paper; A. Gray designed the study and helped write the paper.

Acknowledgements. Funding for this research was provided by the National Environment Research Council (project number NE/J006289/1). Additional support was kindly provided by Jane and David Philbrick. A large number of individuals and organisations provided us with information on wildfire events but we are particularly grateful to the England and Wales Wildfire Forum, the Knowledge for Wildfire project at the University of Manchester and Michael Bruce. Access to field study sites and logistical support were provided by United Utilities, Yorkshire Water, the National Trust, Finzean Esate, and Forestry Commission Scotland. Field data collection was completed with the assistance of Sophie Philbrick. Two anonymous reviewers helped us improve our manuscript

Edited by: A. Rammig

\section{References}

Allen, K. A., Harris, M. P. K., and Marrs, R. H.: Matrix modelling of prescribed burning in Calluna vulgaris-dominated moorland: short burning rotations minimize carbon loss at increased wildfire frequencies, J. Appl. Ecol., 50, 614-624, 2013.

Bates, D., Maechler, M., Bolker, B., and Walker, S.: lme4: Linear mixed-effects models using Eigen and S4. R package version 1.1-7, http://CRAN.R-project.org/package=lme4 (last access: 14 January 2016), 2014. 
Bonn, A., Allott, T., Hubacek, K., and Stewart, J.: Drivers of Environmental Change in the Uplands, Routledge, London, UK, 2009.

Bradley, R. I., Milne, R., Bell, J., Lilly, A., Jordan, C., and Higgins, A.: A soil carbon and land use database for the United Kingdom, Soil Use Manage., 21, 363-369, 2005.

Clay, G. D. and Worrall. F.: Charcoal production in a UK moorland wildfire - how important is it?, J. Environ. Manage., 92, 676682, 2011.

Davies, G. M., Gray, A., Hamilton, A., and Legg, C.J.: The future of fire management in the British uplands, Int. J. Biodiv. Sci. Manage., 4, 127-147, 2008a

Davies, G. M., Legg, C. J., Hamilton, A., and Smith, A. A.: Using visual obstruction to estimate heathland fuel load and structure, Int. J. Wildland Fire, 17, 380-389, 2008b.

Davies, G. M., Smith, A. A., McDonald, A. J., Bakker, J. D., and Legg, C. J.: Fire intensity, fire severity and ecosystem response in heathlands: factors affecting the regeneration of Calluna vulgaris, J. Appl. Ecol., 47, 356-365, 2010.

Davies, G. M., Gray, A., Rein, G., and Legg, C. J.: Peat consumption and carbon loss due to smouldering wildfire in a temperate peatland, Forest Ecol. Manag., 308, 136-144, 2013.

de Groot, W. J., Pritchard, J. M., and Lynham, T. J.: Forest floor fuel consumption and carbon emissions in Canadian boreal forest fires, Can. J. For. Res., 39, 367-382, 2009.

Ellison, A. M., Gotelli, N. J., Inouye, B. D., and Strong, D. R.: P values, hypothesis testing, and model selection: it's déjà vu all over again, Ecology, 95, 609-610, 2014.

Faraway, J. J.: Extending the Linear Model with R: Generalized Linear, Mixed Effects and Nonparametric Regression Models, Chapman and Hall/CRC, Boca Raton, FL, USA, 2005.

Fernandes, P. M., Catchpole, W. R., and Rego, F. C. Shrubland fire behaviour modelling with microplot data, Can. J. Forest Res., 30, 889-899, 2000.

Gallego-Sala, A. V. and Prentice, I. C.: Blanket peat biome endangered by climate change, Nature Climate Change, 3, 152-155, 2012.

Grant, M. C., Mallord, J., Stephen, L., and Thompson, P. S.: The costs and benefits of grouse moor management to biodiversity and aspects of the wider environment: a review, RSPB Research Report Number 43, RSPB, Sandy Bedfordshire, UK, http://www.rspb.org.uk/Images/grant_mallord_ stephen_thompson_2012_tcm9-318973.pdf (last access: 14 January 2016), 2012.

Hogg, P., Squires, P., and Fitter, A. H.: Acidification, nitrogen deposition and rapid vegetational change in a small valley mire in Yorkshire, Biol. Conserv., 71, 143-153, 1995.

Holden, J., Chapman, P. J., and Labadz J. C.: Artificial drainage of peatlands: hydrological and hydrochemical process and wetland restoration, Prog. Phys. Geog., 28, 95-123, 2004.

Hollis, J. J., Matthews, S., Anderson, W. R., Cruz, M. G., and Burrows, N. D.: Behind the flaming zone: Predicting woody fuel consumption in eucalypt forest fires in southern Australia, Forest Ecol. Manag., 261, 2049-2067, 2011.

Johnson, P. C. D.: Extension of Nakagawa and Schielzeth's $\mathrm{R}^{2}$ GLMM to random slopes models, Methods Ecol. Evol., 5, 944946, 2014.

Kaat, A. and Joosten, H.: Factbook for UNFCCC policies on peat carbon emissions, Wetlands International, Wageningen, the Netherlands, http://www.wetlands.org/Portals/0/publications (last access: 19 January 2016), 2009.

Kasischke, E. S. and Johnstone, J. F.: Variation in postfire organic layer thickness in a black spruce forest complex in interior Alaska and its effects on soil temperature and moisture, Can. J. Forest Res., 35, 2164-2177, 2005.

Kettridge, N., Turetsky, M. R., Sherwood, J. H., Thompson, D. K., Miller, C. A., Benscoter, B. W., Flannigan, M. D., Wotton, B. M., and Waddington, J. M.: Moderate drop in water table increases peatland vulnerability to post-fire regime shift, Sci. Rep., 5, 8063, doi:10.1038/srep08063, 2015.

Key, C. H. and Benson, N. C.: Landscape Assessment LA Sampling and Analysis Methods. General Technical Report RMRS-GTR164-C, USDA Forest Service Rocky Mountain Research Station, Fort Collins, CO, USA, http://www.fs.fed.us/rm/pubs/rmrs_ gtr164/rmrs_gtr164_13_land_assess.pdf (last access: 14 January 2016), 2006.

Kitchen, K., Marno, P., Legg, C. J., Bruce, M., and Davies, G. M.: Developing a fire danger rating system for the United Kingdom, Forest Ecol. Manag., 234S1, S21, doi:10.1016/j.foreco.2006.08.037, 2006.

Krivtsov, V., Gray, A., Valor, T., Legg, C. J., and Davies, G. M.: The fuel moisture content of peat as a fuel in relation to meteorological factors, WIT Trans. Ecol. Envir., 119, 193-200, 2008.

Legg, C. J., Davies, G. M., Marno, P., and Kitchen, K.: Developing a Fire Danger Rating System for the UK: FireBeaters final report, Report to the Scottish Wildfire Forum, https://www.era.lib.ed.ac. uk/handle/1842/3011 (last access: 14 January 2016), 2007.

Maltby, E., Legg, C. J., and Proctor, M. C. F.: The ecology of severe moorland fire on the North York Moors: Effects of the 1976 fires, and subsequent surface and vegetation development, J. Ecol., 78, 490-518, 1990.

Miller, J. D. and Thode, A. E.: Quantifying burn severity in a heterogeneous landscape with a relative version of the delta Normalized Burn Ratio dNBR, Remote Sens. Environ., 109, 66-80, 2007.

Mitra, S., Wassmann, R., and Vlek, P. L. G.: An appraisal of global wetland area and its organic carbon stock, Curr. Sci., 88, 25-35, 2005.

Moore, P. D.: The future of cool temperate bogs, Environ. Conserv., 29, 3-20, 2002.

Nakagawa, S. and Schielzeth, H.: A general and simple method for obtaining $R^{2}$ from generalized linear mixed-effects models, Methods Ecol. Evol., 4, 133-142, 2013.

Ostle, N. J., Levy, P. E., Evans, C. D., and Smith, P.: UK land use and soil carbon sequestration, Land Use Policy, 26S1, S274S283, 2009.

Poulter, B., Christensen Jr., N. L., and Halpin, P. N.: Carbon emissions from a temperate peat fire and its relevance to interannual variability of trace atmospheric greenhouse gases, J. Geophys. Res.-Atmos., 111, D06301, doi:10.1029/2005JD006455, 2006.

R Development Core Team: R: A language \& environment for statistical computing. R Foundation for Statistical Computing, Vienna, Austria, http://www.R-project.org (last access: 14 January 2016), 2014.

Rodwell, J. S.: British Plant Communities. Volume 2. Mires \& heaths, Cambridge University Press, Cambridge, UK, 1991. 
Santander Meteorology Group: fume: FUME package, R package version 1.0, http://CRAN.R-project.org/package=fume (last access: 14 January 2016), 2012.

Schepers, L., Haest, B., Veraverbeke, S., Spanhove, T., Vanden Borre, J., and Goossens, R.: Burned area detection and burn severity assessment of a heathland fire in Belgium using airborne imaging spectroscopy (APEX), Remote Sens., 6, 18031826, 2014.

Schielzeth, H. and Forstmeier, W.: Conclusions beyond support: overconfident estimates in mixed models, Behav. Ecol., 20, 416420, 2009.

Scottish Government: The Muirburn Code, Scottish Government, Edinburgh, 2011.

Shetler, G., Turetsky, M. R., Kane, E., and Kasischke, E.: Sphagnum mosses limit total carbon consumption during fire in Alaskan black spruce forests, Can. J. Forest Res., 38, 2328-2336, 2008.

Stace, C.: New Flora of the British Isles, Cambridge University Press, Cambridge, UK, 1997.

Turetsky, M. R., Benscoter, B., Page, S., Rein, G., van der Werf, G. R., and Watts, A.: Global vulnerability of peatlands to fire and carbon loss, Nat. Geosci., 8, 11-14, 2015.
Van Wagner, C. E.: Development and structure of the Canadian Forest Fire Weather Index System, Forestry Technical Report 35, Canadian Forestry Service, Ottawa, 1987.

Watts, A. C. and Kobziar, L. N.: Smoldering combustion and ground fires: ecological effects and multi-scale significance, Fire Ecol., 9, 124-132, 2013.

Worrall, F., Rowson, J. G., Evans, M. G., Pawson, R., Daniels, S., and Bonn, A.: Carbon fluxes from eroding peatlands - the carbon benefit of revegetation following wildfire, Earth Surf. Proc. Land., 36, 1487-1498, 2011.

Worrall, F., Clay, G. D., and May, R.: Controls upon biomass losses and char production from prescribed burning on UK moorland, J. Environ. Manage., 120, 27-36, 2013.

Yu, Z., Loisel, J., Brosseau, D. P., Beilman, D. W., and Hunt, S. J.: Global peatland dynamics since the Last Glacial Maximum, Geophys. Res. Lett., 110, L13402, doi:10.1029/2010GL043584, 2010. 